\title{
Differential Therapeutic Responses to DBT Skills Training and Validation: A Case Study
}

\author{
Graham S. Danzer, Simon Ferber \\ California School for Professional Psychology (CSPP), Alliant International University, San Francisco, USA \\ Email: gemineyeX3@hotmail.com
}

Received 20 January 2014; revised 21 February 2014; accepted 12 March 2014

Copyright $@ 2014$ by authors and Scientific Research Publishing Inc.

This work is licensed under the Creative Commons Attribution International License (CC BY). http://creativecommons.org/licenses/by/4.0/

(c) (i) Open Access

\begin{abstract}
There is some debate in clinical circles about whether therapy should be oriented more to the client's subjective emotional needs or to the client's need for therapeutic direction and problem solving. Although not a true dichotomy, clinicians often orient more strongly to one of the aforementioned strategies or the other. Dialectical behavior therapy (DBT) offers a framework to practice both strategies, as it emphasizes both validation and skills training. It is hypothesized that either the validation, as an example of meeting client's subjective emotional needs, or the skills training accounts for more of the therapeutic change in individuals with borderline personality disorder (BPD). This hypothesis is explored through the case of Teresa, a borderline client who received therapy that aligned with the principles of DBT. She seemed to respond most favorably to basic empathic connection and a subjective sense of being understood. Contrastingly, she tended to recoil from skills-focused interventions. Based on these results, limitations and implications for future research are proposed.
\end{abstract}

\section{Keywords}

Cultural Issues, Gender Issues-Female, Trauma, Victim, Intimate Partner Violence, Treatment, Hispanic/Latino-Race

\section{Introduction}

I have noticed an ongoing, and yet subtle debate in clinical circles regarding whether clients who present for psychotherapy should predominantly receive treatment that is 1) oriented to their subjective, emotional needs (for validation and understanding), or 2) is more directive and oriented to problem solving. Although neither approach is antithetical (and clinicians often integrate them), I have sensed that a majority of my colleagues who work with clients with borderline personality disorder (BPD) have been more strongly oriented towards one 
strategy or the other. This has led me to wonder which strategy is more beneficial to borderline clients who are likely to benefit from both client-centered and directive interventions.

I will explore this aforementioned dilemma by presenting the case of a therapy client with borderline personality disorder who I intuitively worked with in a way that aligned with the validating and skills-training techniques of dialectical behavior therapy (DBT). I will first present a brief outline of borderline personality disorder and a DBT approach to treatment. Then, I will present Teresa's case and conceptualize key interchanges, hypotheses, and outcomes through the theory and research findings in support of it. In particular, I will discuss how Teresa responded when I instinctively validated her emotional experiences and how she responded to my more directive attempts at skill building and problem solving. This is important to my larger subject matter because validation and skills-training are core operating principles of DBT and can therefore be thought of as a microcosm of my proposed therapeutic dilemma. My hope is that this case will encourage further (and of course larger) study on which DBT strategy accounts for the most therapeutic change in clients with BPD.

\section{Borderline Personality Disorder}

Borderline personality disorder (BPD) is a psychiatric disorder characterized by chronic instability in a) social relationships, b) affect regulation, and c) self-image (American Psychiatric Association, 2013). Marsha Linehan (1993) pioneered research on this disorder, identifying that the affective instability is the core symptom from which all other borderline symptoms manifest. Given a lack of solid regulatory capacities, borderlines attempt to regulate through maladaptive coping strategies that are also their primary behavioral symptoms, including a) idealizing-devaluing, b) self-harm, c) substance abuse, and d) becoming enraged at others (Chapman, Gratz, \& Brown, 2006; Nock \& Prinstein, 2004). Recent research confirms the validity and reliability of these ideas (Martín-Blanco, Soler, Villalta, Feliu-Soler, \& Elices, 2014; Tragesser, Solhan, Schwartz-Mette, \& Trull, 2007). I will now briefly discuss the trauma and self-injury and considerations of borderline pathology as they frequent the literature on the subject and will be shown to have implications for my case.

\subsection{Self-Injury}

The DSM-5 describes self-inflicted injury as one of the hallmark symptoms of BPD (American Psychiatric Association, 2013). Research confirms that 70\% - 75\% of those afflicted with BPD have histories of engaging in self-injurious behavior (Gunderson \& Links, 2008; Joyce, Light, Rowe, Cloninger, \& Kennedy, 2010). Self-injury is often classified into three types: non-suicidal self-injury (NSSI), ambivalent suicide attempts, and suicide attempts (Linehan, 1986; Brown, Comtois, \& Linehan, 2002). As originally theorized by Linehan (1993), recent research supports that borderlines habitually engage in NSSI in order to a) feel better, b) distract themselves, c) punish themselves, d) express anger, or e) gain interpersonal influence (Lloyd-Richardson, Perrine, Dierker, \& Kelley, 2007; Brown et al., 2002; Zanarini, Laudate, Frankenburg, Wedig, \& Fitzmaurice, 2013). When borderlines make serious suicide attempts, they are often motivated by the desire to a) relieve negative emotions, or b) save others from the emotional pain inflicted upon them by the borderline symptoms (Brown et al., 2002).

\subsection{Trauma}

Linehan (1993) originally theorized that borderlines are born with an emotionally labile temperament that is exasperated by the interactive effect of an invalidating childhood environment and traumatic events. Research confirms that $81 \%$ of borderlines have experienced emotional, physical, or sexual abuse in early life, and that comorbidity rates of BPD and PTSD range from 24.2\% - 30.2\% (Pagura, Stein, Bolton, \& Cox, 2010; Goldman, D’Angelo, DeMaso, \& Mezzacappa, 1992; Herman, Perry, \& Van der Kolk, 1989; Ogata, Silk, Goodrich, \& Lohr, 1990; Zanarini, Gunderson, Marino, \& Schwartz, 1989). According to Linehan (1993), the association of BPD and trauma should encourage clinicians to conceptualize BPD as a trauma-related syndrome.

\section{DBT}

Dialectical behavior therapy was originally designed by Linehan (1993) as a treatment for the self-injurious behavior of women with borderline personality disorder. DBT builds upon traditional cognitive behavioral therapy, though more particularly emphasizes a dialectical philosophy, validation, and skills training. The dialectical 
philosophy discourages the notion of a universal, objective reality, and encourages consideration that multiple, subjective realities co-exist (Linehan, 1993). Clients are taught skills in four modules: mindfulness, emotional regulation, distress tolerance, and interpersonal skills training (Linehan, 1993). I will primarily discuss mindfulness because most recent research has been on this aspect of the treatment.

\subsection{Mindfulness}

Mindfulness helps to build the therapeutic alliance by increasing the borderline client's non-judgmental awareness and acceptance of a) their emotions, b) difficult therapeutic interchanges, and c) the often difficult and emotionally painful process of therapeutic change (Swales, 2009; Panos, Jackson, Hasan, \& Panos, 2014; Baldwin, Wampold, \& Imel, 2007; Swann, Stein-Serussi, \& Giesler, 1992). In turn, this increased tolerance and awareness helps to prevent early drop out, which ranges from $12 \%$ to $46 \%$ for individuals with BPD (Perroud, Uher, Dieben, Nicastro, \& Huguelet, 2010; Rüsch, Schiel, Corrigan, Leihener, Jacob et al., 2008). Mindful awareness of emotions can also be thought of as a protective factor against borderline symptom exasperation, as it a) decreases the intensity of emotions, b) decreases borderlines' propensity to make unhealthy attempts to control, suppress, or avoid their emotions, c) decreases borderlines' over-focus on negative emotions, and d) increases the flow of positive emotions (Cheavens, Rosenthal, Daughters, Nowak, Kosson et al., 2005; Kruedelbach, McCormick, Schulz, \& Grueneich, 1993; Lynch, Robins, Morse, \& MorKrause, 2001; Davidson, Kabat-Zinn, Schumacher, Rosenkranz, Muller et al., 2003; Neacsiu, Lungu, Harned, Rizvi, \& Linehan, 2014; Arntz, Appels, \& Sieswerda, 2000; Sieswerda, Arntz, Mertens, \& Vertommen, 2007; Wingenfeld, Mensebach, Rullkoetter, Schlosser, Schaffrath et al., 2009; Lynch, Chapman, Rosenthal, Kuo, \& Linehan, 2006).

\subsection{Research Findings in Support of the DBT Approach to Treating BPD}

DBT is a well-established and empirically-supported therapy for the treatment of BPD (Bloom, Woodward, Susmaras, \& Pantalone, 2012). More specifically, DBT has outperformed treatment as usual approaches in clinical trials, and has outperformed medication approaches in research on reducing self-injurious behavior, primarily as a result of the skills training (Bloom et al., 2012; Linehan, Armstrong, Suarez, Allmon, \& Heard, 1991; Linehan, Comtois, Murray, Brown, \& Gallop, 2006; Neacsiu, Rizvi, \& Linehan, 2010).

Research supports that DBT helps borderlines become more capable of regulating their emotions as a result of decreasing a) hopelessness, b) general distress, c) behavioral impulsivity, and d) problematic expressions of anger (Iverson, Shenk, \& Fruzzetti, 2009; Soler, Pascual, Tiana, Cebrià, Barrachina et al., 2009; Koons, Chapman, Betts, O’Rourke, Morse et al., 2006; Axelrod, Pereplethikova, Holtzman, \& Sinha, 2011; Davenport, Bore, \& Campbell, 2010; DeVylder, 2010; van den Bosch, Koeter, Stijnen, Verheul, \& van den Brink, 2005). Improvements in emotional regulation are credited as the core mechanism of therapeutic change in clients with BPD (Lynch et al., 2006). Research also supports the efficacy of DBT in treating BPD that co-occurs with PTSD, as well as the treatment of trauma symptoms in and of themselves (Harned, Jackson, Comtois, \& Linehan, 2010; Becker \& Zayfert, 2001).

\section{Teresa}

When I first met Teresa, I noticed that she was as attractive as she was sad. She was a Latina in her early 20s with a deep, rich complexion, long black hair, and freckles that seemed saturated by tears. She stared down through the floor as if she felt completely hopeless. Within a few short minutes, her sadness nearly overwhelmed me. I wished I could help her, but uncharacteristically doubted my ability to do so.

I was relieved to begin a series of intake questions. It was comforting to distract myself from the emotional resonance and focus on dispassionate questions and answers. I remember feeling inclined to rush through the session and finish it as quickly and painlessly as possible.

Teresa informed me that she had been mandatorily referred to my county mental health clinic by her county welfare worker, who was concerned about her repeated conflicts with other clients in the welfare office and difficulty turning in county paperwork on time. Teresa added that, when she was confronted about these difficulties, she felt terrible and cried uncontrollably in spite of the embarrassment. She elaborated that she was desperate to understand what was wrong with her. She expressed this desire by repeatedly exclaiming: "Why does this keep happening?!” Several months of this led Teresa's welfare worker to insist that she come to my clinic for an as- 
sessment. Looking back on it, this instability in affect and self-image is consistent with the pattern symptom constellation of BPD (American Psychiatric Association, 2013).

In the moment, I took Teresa's questions literally. Over the next half hour I joined her in exploring possible causes of her various interpersonal problems and possible solutions to them. I asked when her problems started, when they tended to increase in severity, and what helped her cope and regulate in times of emotional crisis. These assessment questions are consistent with the DBT framework for the initial stage of therapy (Linehan, 1993).

In response to each question I asked, Teresa became progressively more frantic in the search to discover what was troubling her. We discussed her unsuccessful efforts to get stable on psychiatric medications, engage in alternative therapies, and to work through painful emotions by utilizing self-care practices such as meditation and progressive relaxation. Teresa also mentioned having been hospitalized for psychiatric reasons on at least 10 occasions, though quickly changed subjects in response to my subtle, affectual display of interest. I sensed that it would be better for the development of our relationship to assume that she would tell me the details of her hospitalizations at some point in the future if I really needed to know. This response is consistent with the DBT principles of reciprocity and genuineness in the relationship (Burckell \& McMain, 2011). Accordingly, she seemed to relax a little and began to engage in what felt like a healthier introspection about her relational problems with family members, though quickly returned to what seemed like pressured attempts to problem solve.

We were about a half hour into our first session and none of the various problem solving efforts seemed to be helping Teresa find the sense of resolution she was looking for. Teresa seemed to have two objections to every possible solution to her various life problems. For example, when discussing her strained relationships with her family members, she began to consider different ways that she could speak up to them. Then, she would immediately dismiss her efforts as pointless because her family members would not listen to her, which suggested the possibility of a communication skills deficit.

The hopelessness of our first session up to that moment seemed to be making Teresa feel even more anxious, which lead me to feel more anxious as well. It was as if the harder we tried to assess and find solutions to her problems, the further away we got from any real sense of resolution. By the end of the session, I was in shambles. For a brief moment, I reflected on some of what Teresa had told me in the midst of her anxious flurries and my efforts to help her problem solve. She told me that she had been molested by a neighbor when she was six, had been in a physically abusive relationship in her teenage years, and had a mentally ill mother who refused psychiatric care and tended to be in and out of her life. I felt a compelling need to take emotional care of Teresa, but doubted my ability to do so. This sense of hopelessness and powerlessness is a common, potentially therapy-interfering response to borderline projective and splitting processes (Rigas, 2008; Coifman, Rafaeli, Berenson, \& Downey, 2012). Teresa's history of early life trauma and attachment deficits, related impairments in self-image and interpersonal skills, and present-day depressive and anxiety symptoms is also consistent with the expected profile of an individual with borderline personality (Gaher, Hofman, Simons, \& Hunsaker, 2013).

When she arrived at my office for our next session, I was quite surprised and uncomfortable to see that she was ornately attired and barely contained in a skirt that left little to the imagination. I was concerned about how best to respond, so as to avoid reinforcing a sexualized dynamic that Teresa seemed to be pulling for and also avoid shaming her. I did this by averting my gaze uncomfortably, though trying my best not to look like I was uncomfortable.

Teresa started our session by telling me she was upset with her boyfriend. He lived far away and had not made a satisfactory effort to spend time with her and her infant daughter. She seemed very angry and spoke in an aggressive and forceful manner. I reflected back to her that all of this must be very hard for her to love someone who didn't seem to be putting any effort into their relationship. This reflection led Teresa to relax in a positive way, as is predicted by DBT theories about borderlines' appreciation for being understood and accepted (Burckell \& McMain, 2011).

I then asked Teresa if she had ever addressed this issue with her boyfriend directly. She sighed in despair and nodded affirmatively, explaining that doing so usually lead to an argument and him not seeing her for several days after. As she described this pattern interchange, she looked very sad, a sadness I quietly wished I could fix or run away from.

Teresa also told me that she was having a hard time finding a job, was becoming less and less emotionally satisfied with her relationship with her boyfriend, and was feeling frustrated with her parents for being very dismissive and critical of her. She described her father as always high on marijuana and her mother as always mi- 
serably depressed or psychotically talking to herself. All of this seemed to make Teresa feel very lost and alone, which is consistent with the theory that borderlines experience chronic emptiness in relation to longstanding attachment deficits (Eastwick \& Grant, 2005).

Frequently, when I would sit and listen to Teresa without interrupting her, she would jump frantically from one topic to the next, and would become progressively more overwhelmed and angry. In turn, this made me feel overwhelmed. Sometimes, I would interrupt her lengthy disclosures and ask her questions or gently direct her towards communication skills and other problem-solving strategies. I attempted to do this gently, though with overriding emphasis on instruction, as is consistent with DBT skills training approaches (Linehan et al., 2006).

In response, Teresa would sink further back into her chair and stare at me as if she was listening in order to be polite, though waiting for me to finish so that she could tell me more about her suffering. This negative response to my attempts to help her build skills could have related to my timing or delivery, though is also consistent with an early critique of DBT noted in Beck, Freeman, Davis, and associates (2004): that DBT (i.e. the skills interventions) may be effective ways to help borderlines behave better, though they often self-report that the treatment does not help them feel better. Teresa's negative response to my last intervention lead me to feel very defeated about the possibility that I was not helping her feel better or solve her problems. Furthermore, Teresa only attended roughly half of her therapy sessions.

Just when I was sure things couldn't get any worse in my work with her, she stopped coming to her sessions all together. More specifically, she missed several weeks of therapy in a row without calling in ahead of time. I wondered to myself if I had done something wrong. When I would call to find out what happened, she would usually tell me that she did not attend therapy because she was either busy with other affairs or was feeling physically ill. Usually, I tried to empathize with her various struggles. However, as her absence from therapy continued, I was feeling increasingly frustrated with her. Beneath my frustration, I felt rejected and abandoned, having momentarily forgotten that at least intermittent therapeutic disengagement is fairly typical of this population (Panos et al., 2014).

I did remember (perhaps more importantly) that I needed to carefully hold on to my frustration and not let it out on Teresa. My concern was that, if I let my frustration out on her, I would become like all the other unsupportive others in her life. I hypothesized that I would need to be more patient and understanding if I wanted to have a deeper relationship with her. Meanwhile, I felt like I was trying to chase her back into therapy, though I sensed a paradoxical opportunity to build our relationship even as we were somewhat disengaged.

I decided to act on this premonition when the timing felt right. In one of our many phone conversations in between missed sessions, I asked Teresa how she felt her therapy was going. She reported feeling as though she was not getting any better and routinely spoke to her mother about the hopelessness of her life. Her mother told her that she needed a therapist who was really willing to "go through it" with her, meaning someone who could help her open up emotionally and become vulnerable. Her mother seemed concerned that this would be emotionally draining for the therapist as well. I reflected to myself that Teresa's mother was probably right.

Without thinking, I told Teresa that I would be willing to "go through it with her" if she was ready to let me. I heard her sigh on the other end of the phone. Then, there was a long silence. I wanted to know what she was thinking in those moments, but I felt obligated not to interrupt her. We then casually conversed for a couple more minutes before hanging up.

Thereafter, Teresa began to attend her sessions much more regularly and wore noticeably more clothing. I almost wanted to inquire about this, but elected not to because I couldn't think of any way to do this that wouldn't be shaming. Her positive response is consistent with DBT theory that predicts increased engagement in response to transparency in the therapeutic relationship and dialogue about the subjective meaning that the client attributes to the relationship (Burckell et al., 2011).

In this middle phase of our work together, Teresa often expressed concern about her daughter's aggressive behavior at school, her father having lost his job and resigning himself to the couch and daily marijuana use, and her myriad of psycho-somatic pains and bodily symptoms. She seemed most worried about not knowing why she was having these bodily symptoms and was scared that they might be symptoms of Lupus, which she had learned about in high school. When I listened supportively, she fairly demanded a quicker resolution. When I tried to help her problem solve, she looked at me as if I might have done something wrong. I also remember feeling very anxious about an underlying sense of despair that was rapidly making its way to the surface. Whereas this type of anxiety would usually compel me to take corrective, concrete action, about nine months into my work with Teresa, suddenly, finally, I got it. 
“Teresa.” I asked her: "Do you ever feel like nothing is ever going to get better, which is really scary, and so you have to keep trying different ways of fixing things but nothing works right, and that makes you wanna give up?” "YEAH!” She fairly yelped, leaning forward in her chair, sitting up more rigidly, and staring hard at me as if suddenly freed from an invisible prison. She then sat back, sunk even further back into her chair, and began to breathe more slowly and calmly. It felt to me like this might have been the first time that she felt really, deeply understood. I too couldn't help but to breathe a sigh of relief. That was a moment in our therapeutic work that seemed to last much longer. Somehow, after that, we were much closer.

Since then, in the last year or so, Teresa has rarely missed a session. She occasionally dresses more provocatively, but usually when the hot weather justifies wearing less clothes. In session, she also tends to stay focused on what she is most worried about rather than introducing one topic and then rapidly changing from one topic to the next. This tells me that, after this interchange, she might have been more comfortable with me and might even be better able to use our relationship to help her regulate enough to process her experiences more coherently. Her positive response to my last intervention is consistent with research findings in support of mindful interventions and interactions helping borderlines regulate their affect (Swales, 2009).

Nevertheless, Teresa has continued to struggle mightily. She often tells me about experiencing odd bodily symptoms and what may be infections. These symptoms scare her immensely, though she reports having had so much contact with doctors and emergency rooms that she is reluctant to seek medical care. After talking about her health problems, she sometimes mentions her various traumas. The traumas she has mentioned include her having been a former gang member who had been shot at and gang raped, and having been abducted and then sexually abused when she was seven. She has only mentioned these traumas once or twice in her four years of therapy with me. After briefly mentioning these traumas, she usually changes the subject to something less vulnerable, an emotional avoidance strategy that is consistent with the expected symptom profile of someone who has borderline personality and co-occurring PTSD (Steil, Dyer, Priebe, Kleindienst, \& Bohus, 2011).

When Teresa brings up her traumas and then moves on to other subjects, she often talks about the casual, romantic relationships that she seeks out more aggressively when she feels less emotionally connected to her longtime boyfriend. She reports that these casual relationships tend to give her some of the validation that she doesn't get from her boyfriend.

After discussing her romantic relationships for between 10 and 20 minutes, she usually moves on to discuss other areas of her life that she feels distressed about, including her struggles with finding and maintaining employment. She is very sensitive to criticism and therefore struggles with taking direction from her supervisors. My sense is that Teresa often gets confused or distracted at work, which usually leads her supervisors to intervene, which Teresa tends to interpret as criticism, which makes her feel overwhelmed. This combination of limitations makes it particularly difficult for Teresa to function in an employment setting, though would benefit tremendously from skills training in emotional regulation and communication if she could tolerate more therapeutic direction and structure. Her pattern of presenting past traumas and changing the topic of discussion to present, less consequential, struggles (i.e. seeking unhealthy relationships and being criticized at work) is consistent with theories suggesting a commonality in those with PTSD and BPD (Howell, 2014). Now that I think about it, a well-timed insight intervention that targets this dynamic might be in order.

Teresa reports that she is more capable of managing herself when she is working only part-time, though the income that she generates from working part-time is not enough to provide for herself and her daughter. Thus, she is most interested in finding part-time employment where she can sell marijuana. In order to sell marijuana at work, she must make frequent personal calls and departures to meet customers. When Teresa finds employers who are willing to allow her to do this, they are most often older men who make sexual advances upon her. She says that the forbidden nature of these relationships with older (often married) men is somehow attractive, which often leads her to get sexually involved with them. After a relatively short period of time, she feels guilty about cheating on her boyfriend, grows sufficiently disinterested in the casual relationship with the supervisor, and wants that relationship to end. After setting related boundaries, she always seems to get fired for something unrelated. Teresa interprets this chain of events as a symptom of the unfairness of "the male-dominated system," which makes it impossible for women to get ahead. This leads me to feel impatient and irritated, mainly because Teresa has an obvious role in these dynamics. Now that I think about it, her cycle of posttraumatic recreation and victimhood is consistent with the expected relational dynamics of a borderline with PTSD and should therefore be explored in more detail (Howell, 2014). Teresa also has associate's degree in paralegal studies and may therefore be capable of finding more legitimate employment. 
Teresa has told me that being sexual makes her feel powerful and that this is the only way that she feels that she can have any real, executive authority in her life. She has told me that, usually, when she behaves in more sexually provocative ways, men do as she pleases. She says this with a sense of accomplishment, though she also seems to be masking underlying feelings of sadness about her primary romantic relationship not being emotionally deeper and more fulfilling. Her behavior to the contrary is consistent with Linehan's (1993) original theory that borderlines seek validation, control, and interpersonal influence through engaging in high risk behavior, such a self-injury and problematic patterns in relationships.

In session, I have sometimes re-framed Teresa's sexual behavior as a survival strategy. In essence, she is doing what she must do in order to get by, albeit at a cost to her self-esteem. In response, Teresa typically nods her head a little, looks down, relaxes momentarily, and then quickly resumes telling me about how unfair her life is. When feeling this way, she tries to channel her energy into productive activities such as exploring opportunities for continuing education and attending to the emotional needs of her family members. Despite the fundamentally healthy and responsible nature of these behaviors, Teresa becomes more productive in effort to distract herself from painful emotions. She is often too overwhelmed to effectively engage in these behaviors, which leads her to feel confused and irritated. This last dynamic in our sessions is consistent with the theory that borderlines who receive validation can regulate intermittently, though lack the solid internal structure that would be necessary to maintain a regulated state and function more adaptively (Trepanier, Perry, Koerner, Stamoulos, Sheptycki et al., 2013).

This last point reminds me of the significant time I spend in clinical supervision trying to figure out how to help Teresa, which is admittedly diagnostic of borderline attachment (Linehan, 1993). These consultation sessions always leave me feeling hopeful about what I might say to her in the upcoming sessions. My supervisor frequently encourages me to ask Teresa about what she hopes to gain from therapy, what this might suggest she needs to work on outside of therapy, and if she is willing to implement these changes. However, I find myself so flooded with emotion during sessions with Teresa that I have trouble remembering these interventions.

This leads me to our present work together. I remain thoroughly unsure of the degree to which I have been helpful to Teresa, though I do ask her about how she feels her therapy is going at least once every six months. She usually responds to my inquiry by putting up a strong protest, sensing the possibility of disengagement. She reports that, although she sometimes doubts whether she is getting better, she adds that she does not want to start over with another therapist and thinks of me as a best friend. Although not an outcome in and of itself, this definition of our relationship has improved from the meaning she nonverbally attributed by presenting in provocative clothing and having difficulty accepting therapeutic interventions. I also find myself wondering, if I had attempted more validating interventions and less skill-building interventions, would the results of Teresa's therapy, to date, be more significant?

Interestingly, there is a parallel between the feeling of doubt I experience when I feel I haven't helped Teresa, and the way Teresa may feel when attempting to problem solve. Outside of therapy, she becomes anxious or depressed and does her best to approach her problems in a cognitive, rational way. However, her overwhelming emotions interfere with cognitive processes, rendering her unable to problem solve and seeing herself as a failure. In therapy, when our usual problem-solving techniques are not effective, she seems to feel an overwhelming anxiety and helplessness that I sometimes feel with her. Thus, it may be that the chaos I often feel in our relationship is representative of the chaos that Teresa feels inside of herself. From a diagnostic perspective, this would be considered projection, which borderlines use to regain a sense of control and safety (Bateman \& Fonagy, 2003). From a more relational perspective, it may be that Teresa has succeeded in getting me to more deeply understand what it is like to be her. Ultimately, at the inner-most level, this may have been what she wanted all along.

\subsection{Discussion}

Teresa has behaved provocatively throughout our work together. It would be easy to label her as hyper-sexualized and poorly-boundaried, and to dismiss the possibility of deeper meanings of this behavior on the grounds that these are typical symptoms of borderline pathology (American Psychiatric Association, 2013). My experience has been that, when I think about Teresa in this diagnostic way, I feel more comfortable, in control, and emotionally detached in our sessions. Despite the personal comfort this affords me, I have found that my effectiveness with Teresa is contingent upon my emotional resonance with her experiences, as is consistent with 
DBT theories about validation and acceptance in the therapeutic alliance (Burckell et al., 2011). Likewise, I have been more effective in my work with Teresa when I intervene while thinking about her provocative behavior as her best effort to connect with men, which may be a lifelong attachment strategy. Conceptualizing Teresa in this manner has allowed me to contain any unwarranted feelings of sorrow about the way she must think of herself. Further, this way of reframing Teresa's provocative behavior coincides with the principles of the more relationally-oriented theories of borderline pathology (Burckell et al., 2011).

Throughout our therapeutic work, I have tended to take Teresa's disclosures literally and respond pragmatically, neglecting the unspoken material underneath. For example, when she came to her second session in provocative attire and told me she felt unhappy about her relationship with her boyfriend, I inquired about whether she had addressed her concerns with her boyfriend directly. Instead, Teresa may have benefited more significantly if I had intervened with the thought of what her behavior might be saying about her thoughts about our relationship.

I am also considering that the meta-message of Teresa's anxious flurries tends to be that she is scared and doesn't know what to do about the overwhelming nature of her struggles. When I have tried to help her problem solve, such as by educating her about self-care practices and interpersonal communication skills, she tends to emotionally recoil, wait politely until I am done talking, and then try harder to get me to understand what she is going through. When I have emotionally attuned to Teresa without trying to change her feelings, she seems to feel understood and more able to regulate herself. This was particularly evident in the middle, pivotal phase of her therapy.

In summary, Teresa has responded positively to interventions that coincided with the DBT principle of validation, and struggled with my interventions that coincided with the DBT principles of skill-building and behavior change. This supports the contention I made in the beginning of my paper about how Teresa's case would illustrate my aforementioned dilemma of therapeutic approaches.

Although Teresa responded well to validating interventions, I found them difficult to put forth because Teresa so often refers to herself as if she is a helpless victim, which bothers me considerably. My reaction is informative because Teresa often describes her family members and health service providers as irritably pushing her to seek more gainful employment and to focus more on her daughter than on the men she is dating. I concur that these are laudable goals, though I have also noticed that she tends to take such direction as criticism. In turn, she ends up feeling bad about herself and then seeks out less emotionally-healthy relationships in effort to feel better. In essence, she may be setting herself up to be a victim, which is consistent with the expected pathology of one with borderline personality disorder who also has a complex trauma history (Howell, 2014).

Throughout my work with Teresa, I have tried to walk the fine line of helping her take charge of her life through improved self-care and increasing her interpersonal effectiveness, though also reflecting on our interchanges in order to make sure that my more directive instincts are clinically appropriate and not based on my own therapy-interfering reactions. Now that I think about it, when I have been more directive with Teresa I have often felt irritated and less emotionally regulated. My hope is that this realization of what Linehan (1993) calls a "therapy interfering behavior" will help me be more mindfully aware of my reactions to Teresa in future sessions, which is supported by research to improve therapeutic outcomes (Swales, 2009; Baldwin et al., 2007).

\subsection{Limitations and Critique}

The primary limitation of this article is that I have implied that there is a dichotomous relationship between therapeutic validation and skill-building. In fact, DBT incorporates a methodology for both. It also should not be assumed that skill building interventions or therapeutic direction are invalidating.

Although Teresa's more positive reactions to my validating interventions and her negative reactions to my skill building interventions may have to do with my timing and delivery, it is also possible that her differential response has larger implications for DBT research on the treatment of borderlines. In particular, it is possible that increased emphasis on validation (in DBT), and somewhat less of a skills-focused approach might help improve the extent to which borderlines feel better and behave better (in answer to the critique I cited in Beck et al., 2004). However, further research is needed to confirm or disconfirm this hypothesis and control for the risk management considerations inherent in lowering the skills focus that is supported by research to decrease emotional risk factors for problematic behavior (Panos et al., 2014).

I must also concede that, although I have some training in DBT and some meaningful clinical experience with 
individuals with borderline personality disorder, I am not meaning to present my work with Teresa as a perfect case example of this approach. My personal therapeutic style and some of the more clinically significant interchanges in my work with Teresa coincided with some of the core principles of DBT, though my contribution to these interchanges stemmed largely from my intuitions about Teresa's needs. The way in which my validating interventions naturally aligned with the operating principles of DBT and yielded positive responses may be a somewhat tangential form of practice-based evidence in support of the methodology under study.

On that note, Teresa's lack of positive response to my efforts to help her build skills or change her behavior could have had less to do with the general efficacy of the interventions themselves, and more to do with therapeutic alliance and relational factors that are known to be paramount to working with individuals with BPD (Baldwin et al., 2007). I do tend to present with a stronger personality and presence in the therapeutic room and have experienced strong, potentially therapy-interfering sadness, anxiety, and frustration throughout my work with Teresa. Additionally, she has an extensive history of being traumatized by men. Thus, it might be that she emotionally recoils in our sessions, not necessarily because she can't tolerate therapeutic direction or skillsbuilding interventions, but because I have sometimes been directive with her based on my therapy-interfering emotions noted previously. It may also be that she emotionally recoils when she feels invalidated by men, and interprets my attempts at therapeutic direction as additional experiences of a man attempting to control her. This discussion coincides with Linehan's (1993) cautionary words about therapy-interfering behavior.

As I now reflect back on the last four years of our work together, my sense is that Teresa has really wanted me to hear and understand her traumatic suffering. More than anything, she does not want to be alone, and appreciates when I offer her a safe relationship she has lacked elsewhere. In session, I have asked her if this is true and she has readily agreed. This interchange coincides with the theory that borderlines experience chronic emptiness and may highly value departure points from that emptiness. Borderlines frequently cope with chronic emptiness through suicidal behavior, and high risk substance abuse, gambling, and sexual exploits (Chapman et al., 2006; Nock et al., 2004). It may be that my treatment of Teresa's loneliness may be helping her to contain negative emotions and refrain from acting on them in ways that are self-destructive. Although she still engages in plenty of problematic behavior, it is possible that she would have engaged in more problematic behavior if not for her therapy.

My hope is that I will find a way to stay emotionally close to Teresa's experiences and validate her feelings, while also helping her learn new and more effective relational and problem solving skills through my own ability to use them in session with her. Specifically, I would model them to her, rather than teaching them to her. Ultimately, this may be the best way to help Teresa regulate and internalize the skills that can help her function more effectively in the world. This may be the bridge between a more directive, skill-building therapeutic approach and a more emotionally-connected, client-centered approach.

\section{References}

American Psychiatric Association (2013). Diagnostic and Statistical Manual of Mental Disorders (5th ed.). Arlington, VA: American Psychiatric Publishing.

Axelrod, S., Perepletchikova, F., Holtzman, K., \& Sinha, R. (2011). Emotion Regulation and Substance Use Frequency in Women with Substance Dependence and Borderline Personality Disorder Receiving Dialectical Behavior Therapy. American Journal of Drug and Alcohol Abuse, 3, 37-42. http://dx.doi.org/10.3109/00952990.2010.535582

Baldwin, S., Wampold, B., \& Imel, Z. (2007). Untangling the Alliance-Outcome Correlation: Exploring the Relative Importance of Therapist and Patient Variability in the Alliance. Journal of Consulting and Clinical Psychology, 75, 842-852. http://dx.doi.org/10.1037/0022-006X.75.6.842

Bateman, A., \& Fonagy, P. (2003). The Development of an Attachment-Based Treatment Program for Borderline Personality Disorder. Bulletin of the Menninger Clinic, 67, 187-211. http://dx.doi.org/10.1521/bumc.67.3.187.23439

Beck, A., Freeman, A., Davis, D., \& Associates (2004). Cognitive Therapy of Personality Disorder (2nd ed.). New York: Guliford.

Bloom, J., Woodward, E., Susmaras, T., \& Pantalone, D. (2012). Use of Dialectical Behavior Therapy in Inpatient Treatment of Borderline Personality Disorder: A Systematic Review. Psychiatric Services, 63, 881-888. http://dx.doi.org/10.1176/appi.ps.201100311

Brown, M., Comtois, K., \& Linehan, M. (2002). Reasons for Suicide Attempts and Nonsuicidal Self-Injury in Women with Borderline Personality Disorder. Journal of Abnormal Psychology, 111, 198-202. http://dx.doi.org/10.1037/0021-843X.111.1.198 
Burckell, L., \& McMain, S. (2011). Contrasting Client in Dialectical Behavior Therapy for Borderline Personality Disorder: "Marie" and "Dean," Two Cases with Different Alliance Trajectories and Outcomes. Pragmatic Case Studies in Psychotherapy, 7, 246-267. http://dx.doi.org/10.14713/pcsp.v7i2.1090

Cheavens, J., Rosenthal, M., Daughters, S, Nowak, J., Kosson, D., Lynch, T., \& Lejuez, C. (2005). An Analogue Investigation of the Relationships among Perceived Parental Criticism, Negative Affect, and Borderline Personality Disorder Features: The Role of Thought Suppression. Behaviour Research and Therapy, 43, 257-268. http://dx.doi.org/10.1016/j.brat.2004.01.006

Coifman, K., Rafaeli, E., Berenson, K., \& Downey, G. (2012). From Negative to Positive and Back Again: Polarized Affective and Relational Experience in Borderline Personality Disorder. Journal of Abnormal Psychology, 121, 668-679. http://dx.doi.org/10.1037/a0028502

Davenport, J., Bore, M., \& Campbell, J. (2010). Changes in Personality in Pre- and Post-Dialectical Behaviour Therapy Borderline Personality Disorder Groups: A Question of Self-Control. Australian Psychologist, 45, 59-66. http://dx.doi.org/10.1080/00050060903280512

Davidson, R., Kabat-Zinn, J., Schumacher, J., Rosenkranz, M., Muller, D., Santorelli, S., Urbanowski, F., Harrington, A., Bonus, K., \& Sheridan, J. (2003). Alterations in Brain and Immune Function Produced by Mindfulness Meditation. Psychosomatic Medicine, 65, 564-570. http://dx.doi.org/10.1097/01.PSY.0000077505.67574.E3

DeVylder, J. (2010). Dialectical Behavior Therapy for the Treatment of Borderline Personality Disorder: An Evaluation of the Evidence. International Journal of Psychosocial Rehabilitation, 15, 3.

Eastwick, Z., \& Grant, A. (2005). The Treatment of People with “Borderline Personality Disorder”: A Cause for Concern? Mental Health Practice, 8, 38-40. http://dx.doi.org/10.7748/mhp2005.04.8.7.38.c1856

Gaher, R., Hofman, N., Simons, J., \& Hunsaker, R. (2013). Emotion Regulation Deficits and Mediators between Trauma Exposure and Borderline Symptoms. Cognitive Therapy and Research, 37, 466-475.

http://dx.doi.org/10.1007/s10608-012-9515-y

Goldman, S., D’Angelo, E., DeMaso, D., \& Mezzacappa, E. (1992). Physical and Sexual Abuse Histories among Children with Borderline Personality Disorder. The American Journal of Psychiatry, 149, 1723-1726.

Gunderson, J., \& Links, P. (2008). Borderline Personality Disorder: A Clinical Guide (2nd ed.). Arlington, VA: American Psychiatric Publishing, Inc.

Harned, M., Jackson, S., Comtois, K., \& Linehan, M. (2010). Dialectical Behavior Therapy as a Precursor to PTSD Treatment for Suicidal and/or Self-Injuring Women with Borderline Personality Disorder. Journal of Traumatic Stress, 23, 421429. http://dx.doi.org/10.1002/jts.20553

Herman, J., Perry, J., \& Van der Kolk, B. (1989). Childhood Trauma in Borderline Personality Disorder. The American Journal of Psychiatry, 146, 490-495.

Howell, E. (2014). Ferenczi's Concept of Identification with the Aggressor: Understanding Dissociative Structure with Interacting Victim and Abuser States. The American Journal of Psychoanalysis, 74, 48-59. http://dx.doi.org/10.1057/ajp.2013.40

Iverson, K., Shenk, C., \& Fruzzetti, A. (2009). Dialectical Behavior Therapy for Women Victims of Domestic Abuse: A Pilot Study. Professional Psychology: Research and Practice, 40, 242-248. http://dx.doi.org/10.1037/a0013476

Joyce, P., Light, K. J., Rowe, S., Cloninger, C., \& Kennedy, M. (2010). Self-Mutilation and Suicide Attempts: Relationships to Bipolar Disorder, Borderline Personality Disorder, Temperament and Character. Australian and New Zealand Journal of Psychiatry, 44, 250-257. http://dx.doi.org/10.3109/00048670903487159

Koons, C., Chapman, A., Betts, B., O’Rourke, B., Morse, N., \& Robins, C. (2006). Dialectical Behavior Therapy Adapted for the Vocational Rehabilitation of Significantly Disabled Mentally Ill Adults. Cognitive and Behavioral Practice, 13, 146-156. http://dx.doi.org/10.1016/j.cbpra.2005.04.003

Kruedelbach, N., McCormick, R. A., Schulz, S., \& Grueneich, R. (1993). Impulsivity, Coping Styles, and Triggers for Craving in Substance Abusers with Borderline Personality Disorder. Journal of Personality Disorders, 7, 214-222. http://dx.doi.org/10.1521/pedi.1993.7.3.214

Linehan, M. (1986). Suicidal People: One Population or Two? In J. J. Mann, \& M. Stanley (Eds.), Annals of the New York Academy of Sciences: Vol. 487. The Psychobiology of Suicide (pp. 16-33). New York: New York Academy of Sciences.

Linehan, M. (1993). Cognitive-Behavioral Treatment of Borderline Personality Disorder. New York: Guilford.

Linehan, M., Armstrong, H., Suarez, A., Allmon, D., \& Heard, H. (1991). Cognitive-Behavioral Treatment of Chronically Parasuicidal Borderline Patients. JAMA Psychiatry, 48, 1060-1064.

http://dx.doi.org/10.1001/archpsyc.1991.01810360024003

Linehan, M., Comtois, K., Murray, A., Brown, M., Gallop, R., Heard, H., Korslund, K., Reynolds, S., \& Lindenboim, N. (2006). Two-Year Randomized Controlled Trial and Follow-Up of Dialectical Behavior Therapy vs Therapy by Experts 
for Suicidal Behaviors and Borderline Personality Disorder. JAMA Psychiatry, 63, 757-766. http://dx.doi.org/10.1001/archpsyc.63.7.757

Lloyd-Richardson, E., Perrine, N., Dierker, L., \& Kelley, M. (2007). Characteristics and Functions of Non-Suicidal Self-Injury in a Community Sample of Adolescents. Psychological Medicine, 37, 1183-1192. http://dx.doi.org/10.1017/S003329170700027X

Lynch, T., Chapman, A., Rosenthal, M., Kuo, J., \& Linehan, M. (2006). Mechanisms of Change in Dialectical Behavior Therapy: Theoretical and Empirical Observations. Journal of Clinical Psychology, 62, 459-480. http://dx.doi.org/10.1002/jclp.20243

Lynch, T. R., Robins, C., Morse, J. Q., \& Krause, E. D. (2001). A Mediational Model Relating Affect Intensity, Emotion Inhibition, and Psychological Distress. Behavior Therapy, 32, 519-536. http://dx.doi.org/10.1016/S0005-7894(01)80034-4

Martín-Blanco, A., Soler, J., Villalta, L., Feliu-Soler, A., Elices, M., Pérez, V., Arranz, M., Ferraz, L., Alvarez, E., \& Pascual, J. (2014). Exploring the Interaction between Childhood Maltreatment and Temperamental Traits on the Severity of Borderline Personality Disorder. Comprehensive Psychiatry, 55, 311-318. http://dx.doi.org/10.1016/j.comppsych.2013.08.026

Neacsiu, A., Lungu, A., Harned, M., Rizvi, S., \& Linehan, M. (2014). Impact of Dialectical Behavior Therapy versus Community Treatment by Experts on Emotional Experience, Expression, and Acceptance in Borderline Personality Disorder. Behaviour Research and Therapy, 53, 47-54. http://dx.doi.org/10.1016/j.brat.2013.12.004

Neacsiu, A., Rizvi, S., \& Linehan, M. (2010). Dialectical Behavior Therapy Skills Use as a Mediator and Outcome of Treatment for Borderline Personality Disorder. Behaviour Research and Therapy, 48, 832-839. http://dx.doi.org/10.1016/j.brat.2010.05.017

Nock, M., \& Prinstein, M. (2004). A Functional Approach to the Assessment of Self-Mutilative Behavior. Journal of Consulting and Clinical Psychology, 72, 885-890. http://dx.doi.org/10.1037/0022-006X.72.5.885

Ogata, S., Silk, K., Goodrich, S., Lohr, N., Westen, D., \& Hill, E. M. (1990). Childhood Sexual and Physical Abuse in Adult Patients with Borderline Personality Disorder. The American Journal of Psychiatry, 147, 1008-1013.

Pagura, J., Stein, M., Bolton, J., Cox, B., Grant, B., \& Sareen, J. (2010). Comorbidity of Borderline Personality Disorder and Posttraumatic Stress Disorder in the US Population. Journal of Psychiatric Research, 44, 1190-1198. http://dx.doi.org/10.1016/j.jpsychires.2010.04.016

Panos, P., Jackson, J., Hasan, O., \& Panos, A. (2014). Meta-Analysis and Systematic Review Assessing the Efficacy of Dialectical Behavior Therapy (DBT). Research on Social Work Practice, 24, 213-223. http://dx.doi.org/10.1177/1049731513503047

Perroud, N., Uher, R., Dieben, K., Nicastro, R., \& Huguelet, P. (2010). Predictors of Response and Drop-Out during Intensive Dialectical Behavior Therapy. Journal of Personality Disorders, 24, 634-650. http://dx.doi.org/10.1521/pedi.2010.24.5.634

Rigas, D. (2008). Silent Dialogues in the Analytic Relationship. International Forum for Psychoanalysis, 17, 37-43. http://dx.doi.org/10.1080/08037060701676367

Rüsch, N., Schiel, S., Corrigan, P., Leihener, F., Jacob, G., Olschewski, M., Lieb, K., \& Bohus, M. (2008). Predictors of Dropout from Inpatient Dialectical Behavior Therapy among Women with Borderline Personality Disorder. Journal of Behavior Therapy and Experimental Psychiatry, 39, 497-503. http://dx.doi.org/10.1016/j.jbtep.2007.11.006

Sieswerda, S., Arntz, A., Mertens, I., \& Vertommen, S. (2007). Hypervigilance in Patients with Borderline Personality Disorder: Specificity, Automaticity, and Predictors. Behaviour Research and Therapy, 45, 1011-1024. http://dx.doi.org/10.1016/j.brat.2006.07.012

Soler, J., Pascual, J., Tiana, T., Cebrià, A., Barrachina, J., Campins, M., Gich, I., Alvarez, E., \& Pérez, V. (2009). Dialectical Behaviour Therapy Skills Training Compared to Standard Group Therapy in Borderline Personality Disorder: A 3-Month Randomised Controlled Clinical Trial. Behaviour Research and Therapy, 47, 353-358. http://dx.doi.org/10.1016/j.brat.2009.01.013

Steil, R., Dyer, A., Priebe, K., Kleindienst, N., \& Bohus, M. (2011). Dialectical Behavior Therapy for Posttraumatic Stress Disorder Related to Childhood Sexual Abuse: A Pilot Study of an Intensive Residential Treatment Program. Journal of Traumatic Stress, 24, 102-106.

Swales, M. A. (2009). Dialectical Behaviour Therapy: Description, Research and Future Directions. International Journal of Behavioral Consultation and Therapy, 5, 164-177.

Swann, W., Stein-Seroussi, A., \& Giesler, R. (1992). Why People Self-Verify. Journal of Personality and Social Psychology, 62, 392-401. http://dx.doi.org/10.1037/0022-3514.62.3.392

Tragesser, S., Solhan, M., Schwartz-Mette, R., \& Trull, T. (2007). The Role of Affective Instability and Impulsivity in Predicting Future BPD Features. Journal of Personality Disorders, 21, 603-614. http://dx.doi.org/10.1521/pedi.2007.21.6.603 
Trepanier, L., Perry, J., Koerner, A., Stamoulos, C., Sheptycki, A., \& Drapeau, M. (2013). A Study of the Similarity between the Three Models of Interpersonal Functioning of Patients with Borderline Personality Disorder. Submitted as a Brief Research Report. Archives of Psychiatry and Psychotherapy, 15, 55-60.

Van den Bosch, L. C., Koeter, M. J., Stijnen, T., Verheul, R., \& van den Brink, W. (2005). Sustained Efficacy of Dialectical Behaviour Therapy for Borderline Personality Disorder. Behaviour Research and Therapy, 43, 1231-1241. http://dx.doi.org/10.1016/j.brat.2004.09.008

Wingenfeld, K., Mensebach, C., Rullkoetter, N., Schlosser, N., Schaffrath, C., Woermann, F., Driessen, M., \& Beblo, T. (2009). Attentional Bias to Personally Relevant Words in Borderline Personality Disorder Is Strongly Related to Comorbid Posttraumatic Stress Disorder. Journal of Personality Disorders, 23, 141-155. http://dx.doi.org/10.1521/pedi.2009.23.2.141

Zanarini, M. C., Gunderson, J. G., Marino, M. F., Schwartz, E. O., \& Frankenburg, F. R. (1989). Childhood Experiences of Borderline Patients. Comprehensive Psychiatry, 30, 18-25. http://dx.doi.org/10.1016/0010-440X(89)90114-4

Zanarini, M., Laudate, C., Frankenburg, F., Wedig, M., \& Fitzmaurice, G. (2013). Reasons for Self-Mutilation Reported by Borderline Patients over 16 Years of Prospective Follow-Up. Journal of Personality Disorders, 27, 783-794.

http://dx.doi.org/10.1521/pedi_2013_27_115 